\title{
FATAL SPONTANEOUS RUPTURE OF AN AORTIC ANEURYSM IN A YOUNG ADULT
}

\author{
BY \\ A. W. MCCRACKEN AND D. J. STOKER \\ From the Royal Air Force Hospital, Akrotiri, Cyprus
}

(RECEIVED FOR PUBLICATION NOVEMBER 19, 1960)

Dissecting aortic aneurysm is uncommon in young persons. Schnitker and Bayer (1944), in a review of the literature, found 580 reported cases, of which 141 were under the age of 40 years and only 53 in the 21 to 30 age group. Gore (1953) has described the condition in 32 cases, of which 18 were between the ages of 20 and 29 . These were almost exclusively from American sources. Aortic dissecting aneurysm has also been reported in young children (Coleman, 1955), and the relationship of aneurysm to the Marfan syndrome of arachnodactyly, dislocation of the lens, and musculo-skeletal abnormalities is established (Baer, Taussig, and Oppenheimer, 1943 ; Sinclair, Kitchin, and Turner, 1960), especially in the younger age groups, where the aortic lesion appears as one of the manifestations of the mesenchymal degeneration.

\section{CASE Report}

On a hot afternoon in Cyprus, a Royal Air Force technician aged 22 was cycling towards his unit. He was seen to dismount from his bicycle at the roadside by a taxi-driver, who passed the same spot a short time later and noticed that the young man had collapsed. He brought him by car to the station sick quarters, but the man died almost immediately.

His medical history recorded an episode of left chest pain 15 months previously, when a chest radiograph was reported as normal. A Wassermann reaction, following an attack of urethritis, at this time had been negative. He had not complained of any symptoms in the months before his death.

At post-mortem examination, the body showed intense cyanosis of the head. Internally, the pericardium was distended by $600 \mathrm{ml}$. of blood, most of which showed post-mortem coagulation. The site of haemorrhage was in a large fusiform aneurysm of the ascending aorta, which began just above the aortic valve and extended to the origin of the innominate artery (Fig. 1). The aneurysm measured $7 \times 10 \times$ $12 \mathrm{~cm}$. At its upper end anteriorly, there was an irregular tear, $1.5 \mathrm{~cm}$. long, and close to this, internally, the intima had split in two places. There were atheromatous deposits in the aortic intima and in the coronary arteries. The heart and the aortic arch together weighed $385 \mathrm{~g}$. and slight left ventricular hypertrophy was present. The valves showed no abnormality. There were large numbers of dense adhesions between the visceral and parietal pleurae of the left upper lobe. The lungs were very congested, but the other organs were essentially normal. No features suggesting the Marfan syndrome were present.

Sections of the aorta showed intimal proliferation and atheromatous change with gross splitting and disorganization of the elastic lamellae. The lungs showed cardiac failure cells and slight collapse. The renal vessels showed no evidence of hypertensive changes. The histological appearances of the other major organs were essentially normal.

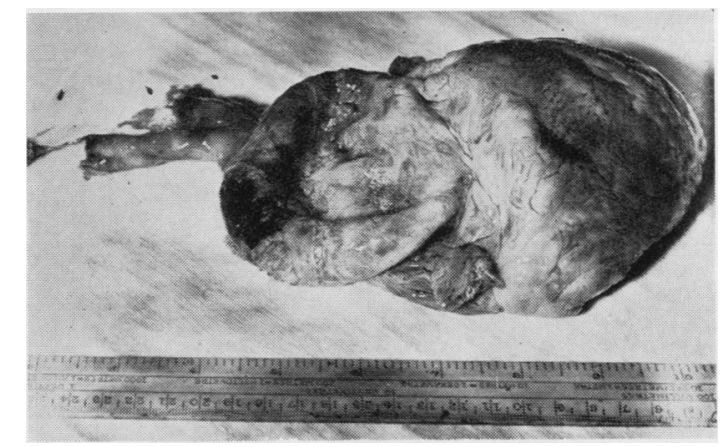

Fig. 1.-After removal of the pericardium, the aneurysm and the site of rupture can be clearly seen.

\section{Discussion}

The underlying histopathology in "spontaneous " rupture of the aorta and aortic dissecting aneurysm is essentially the same (Gore, 1953). The elastic tissue of the aortic media degenerates with splitting and derangement of the elastic lamellae. Actual necrosis occurring in the media is also described (Erdheim, 1929), but this is rare in the experience of Cappell (1951). Mucinous change may also be found on occasion. Very similar appearances are present in the aortic hypoplasia associated with the Marfan syndrome. in which the appearances of degeneration and 
disruption of the elastic layers, disorganized smooth muscle masses, and dilated vascular channels penetrating the media from the adventitia are described (McKusick, 1957). In our case, there was no other evidence of the syndrome and the aortic lesion was a solitary finding.

Gore (1953) does not consider that hypertension is of great import in the production of aortic dissecting aneurysm, although a raised blood pressure is commonly present in the over-40 age group. In this case, there were no hypertensive changes in the renal vessels on histological examination.

The diagnosis of the condition in life may prove difficult. An early diastolic murmur, due to aortic incompetence, is only present when there is dilatation of the aortic ring, which was not found here. Dilatation of the aorta occurs most frequently in the ascending part (Shennan, 1934) and especially at its base. Since this portion is within the pericardial sac, dilatation may not be obvious at first, although pulsation may be seen on radioscopy.

Gore has shown radiologically that these aneurysms may develop over a period of a few months. In this case, a chest radiograph taken 15 months previously was re-examined, but the aortic arch showed no significant abnormality.

It is recognized that in the Marfan syndrome ocular, skeletal, and cardiac abnormalities may occur independently. It is possible that the present case was a forme fruste of the syndrome limited to one abnormality in one system.

\section{SUMMARY}

A case of spontaneous rupture of an aortic aneurysm in a man of 22 is described.

The relative rarity of the condition in this age group, the similarity to dissecting aneurysms, and the possible relationship to the Marfan syndrome are discussed.

Attention is drawn to the rapidity with which $\vec{\sigma}$ the condition can develop.

We wish to thank Group Captain R. M. Cross, Royal Air Force Institute of Pathology and Tropical 을 Medicine, for histological examination, and the Director-General of Medical Services, Royal Air Force, for permission to publish.

\section{REFERENCES}

Baer, R. W., Taussig, H. B., and Oppenheimer, E. H. (1943). Bull. Johns Hopk. Hosp., 72, 309

Cappell, D. F. (1951). Muir's Textbook of Pathology, 6th ed., p. 320 Arnold, London.

Coleman, P. N. (1955). J. clin. Path., 8, 313.

Erdheim, J. (1929). Virchows Arch. path. Anat., 273, 454.

Gore, I. (1953). A.M.A. Arch. Path., 55, 1.

McKusick, V. A. (1957). Circulation, 11, 321.

Schnitker, M. A., and Bayer, C. A. (1944). Ann. intern. Med., 20, 486

Shennan, T. (1934). Spec. Rep. Ser. med. Res. Coun. (Lond.), No. 193.

Sinclair, R. J. G., Kitchin, A. H., and Turner, R. W. D. (1960) Quart. J. Med., n.s., 29, 19. 